\title{
Centros de documentación de televisiones en Catalunya. Estudio de BTV, RTVE, TVC y 8tv
}

\section{Lluís Inarejos}

Javier Guallar

Recibido: 1 de octubre de 2015

Aceptado: 7 de octubre de 2015

\section{Resumen}

Se realiza un estudio comparativo de los departamentos de documentación de las cuatro principales empresas televisivas con presencia en Catalunya: BTV, RTVE, TVC y 8tv. Se estudian los métodos y sistemas de trabajo, considerando los siguientes aspectos: software; selección; análisis documental; digitalización y nuevos flujos de trabajo; usuarios; productos documentales; futuro profesional. Es un estudio cualitativo basado en entrevistas a Tomeu Mas (BTV), Dolors Gonzalo (RTVE), Àngels Serres (TVC) y Caterina Riera (8tv).

\section{Pallabras clave}

Documentación audiovisual, Documentación en televisión, Documentación periodística, Archivos audiovisuales, Documentalistas, Centros de documentación, Digitalización, Profesión.

\section{Documentation centers in catalonian televisions. Case study of BTV, RTVE, TVC and 8tv.}

\section{Albstract}

A comparative study of the documentation departments of the four major television companies in Catalonia was performed: BTV, RTVE, TVC and 8tv. Methods and work systems are studied, considering the following aspects: software; selection; document analysis; digitization and new workflows; users; documentary products; professional future. It is a qualitative study based on interviews with Tomeu Mas (BTV), Dolors Gonzalo (RTVE), Àngels Serres (TVC) and Caterina Riera (8TV).

\section{Keywords}

Audiovisual documentation, TV Documentation, Journalistic documentation, Audiovisual archives, Documentalists, Documentation centers, Digitization, Profession.

http://dx.doi.org/10.5209/rev CDMU.2015.v26.50629 


\section{INTRODUCCIÓN}

El ejercicio de la documentación en las empresas televisivas es una especialidad profesional de amplia trayectoria que ha tenido tradicionalmente su correspondencia en una presencia importante en la bibliografía especializada en documentación, particularmente en España (Castillo Blasco y Soler Monreal, 2014).

En lo que se refiere al ejercicio profesional, la documentación en televisión se concreta en la existencia de centros o departamentos de documentación en las empresas televisivas, de dimensiones que habitualmente están estrechamente relacionadas a las de la organización a la que dan servicio. Por ejemplo, las cadenas televisivas españolas del estudio de Giménez-Rayo y Guallar (2014) tienen secciones de documentación con plantillas que oscilan entre las 38 y las 5 personas. Aunque la crisis económica de los últimos años, de particular impacto en los medios de comunicación, ha ocasionado reducciones de plantillas en muchos casos (y también algún cierre), el ámbito profesional de la documentación en televisión sigue manteniendo una presencia relevante en la mayoría de empresas del sector.

Esta permanencia en el tiempo de la estructura y de las funciones básicas de los departamentos de documentación televisivos, a pesar de situaciones complicadas como las derivadas recientemente de la crisis, no evita que las preocupaciones y los retos de los profesionales de la documentación en televisión evolucionen con el paso del tiempo. Si hace unos años la preocupación fundamental era cómo afrontar la digitalización de los fondos audiovisuales (Hidalgo Goyanes, 2005; Agirreazaldegi-Berriozabal, 2007; Lópezde-Quintana-Sáenz, 2007), los tiempos actuales son particularmente propicios a diversidad de incertidumbres, retos y oportunidades, como se puede comprobar si se consulta la bibliografía de los últimos cinco años. En ella se aprecian las preocupaciones por las nuevas funciones o futuros roles para los documentalistas, su relación con los periodistas y la redacción del medio, la evolución de las tareas de selección o de análisis documental, la evolución de la tecnología, las propuestas de creación de productos documentales, la relación con los usuarios, los archivos audiovisuales en internet, etc. (Caridad Sebastian, 2011; Caldera-Serrano y Arranz-Escacha, 2012; Giménez-Rayo, 2012; Hidalgo Goyanes, 2013; López-deQuintana-Sáenz, 2014; De Mon y Guallar, 2014; Giménez-Rayo y Guallar, 2014; Rubio y Guallar, 2014; Caldera-Serrano, 2015).

Por todo ello, es particularmente necesaria y útil, tanto para los propios profesionales como para investigadores y estudiantes e interesados en el tema, la periódica realización de estudios como el presente sobre la situación de las funciones de este sector altamente especializado de la disciplina de la Información y Documentación, que es la Documentación Audiovisual en Televisión.

\section{OBJETIVO Y MÉTODO}

El presente trabajo tiene como objetivo describir y analizar la situación actual de la documentación en cuatro empresas televisivas de Catalunya: Barcelona Televisió (BTV), Radio Televisión Española (RTVE) en Catalunya, Televisió de Catalunya (TVC) y Vuit tv (8tv), los cuatro televisiones que en Catalunya disponen de centros de documentación y de profesionales documentalistas dando servicio a la producción audiovisual de sus respectivas cadenas. 
En este sentido, el artículo se inscribe en la extensa línea de estudios de caso sobre departamentos de documentación de televisión concretos. Por ejemplo, y citando solo trabajos recientes sobre las televisiones que tratamos en el presente estudio, los artículos de Mas y Martínez (2010), sobre BTV; López de Solís et al (2014) y Muñoz-de-la-Peña-Costero et al (2014) sobre RTVE; y Conesa (2013) sobre TVC (sobre documentación de 8tv no existe todavía bibliografía académica). En esta ocasión no obstante, no se describe o analiza una única organización, que es lo más habitual, sino cuatro, con la intención de poder realizar una aproximación más amplia a la situación de las prácticas documentales en el sector televisivo mediante la comparación de la situación en diversos centros.

Se ha optado por realizar una aproximación cualitativa al objeto de estudio y el trabajo se ha basado en cuatro entrevistas en profundidad con un profesional representante de cada departamento de documentación. Las personas entrevistadas y las fechas de las entrevistas fueron:

- $\quad$ BTV: Tomeu Mas. 4 de marzo de 2015

- RTVE en Catalunya: Dolors Gonzalo. 15 de abril de 2015

- TVC: Àngels Serres. 18 de marzo de 2015

- 8tv: Caterina Riera (con intervenciones de Soraya Lozano). 11 de marzo de 2015

\section{RESULTADOS}

A continuación, se muestran los resultados del estudio cualitativo sobre las cuatro televisiones basado en entrevistas, agrupando los mismos en bloques temáticos. Tras un primer apartado inicial de presentación de los centros, los aspectos estudiados son: software; selección; análisis documental; digitalización y nuevos flujos de trabajo; usuarios; productos documentales; futuro profesional.

En cada apartado se muestra una breve selección de las respuestas obtenidas [1] y a continuación el comentario o análisis de las mismas. 


\section{Presentación de los centros}

Barcelona Televisió (BTV) es una cadena de televisión pública de ámbito local gestionada por el Ayuntamiento de Barcelona. El departamento de documentación de BTV nace en 1994, junto con la creación de la cadena. Mireia Udina es la directora del departamento que actualmente está formado por seis profesionales: cuatro gestores de contenidos y dos documentalistas. Los ámbitos de trabajo donde interviene el departamento son: informativos, deportes y programas de entretenimiento.

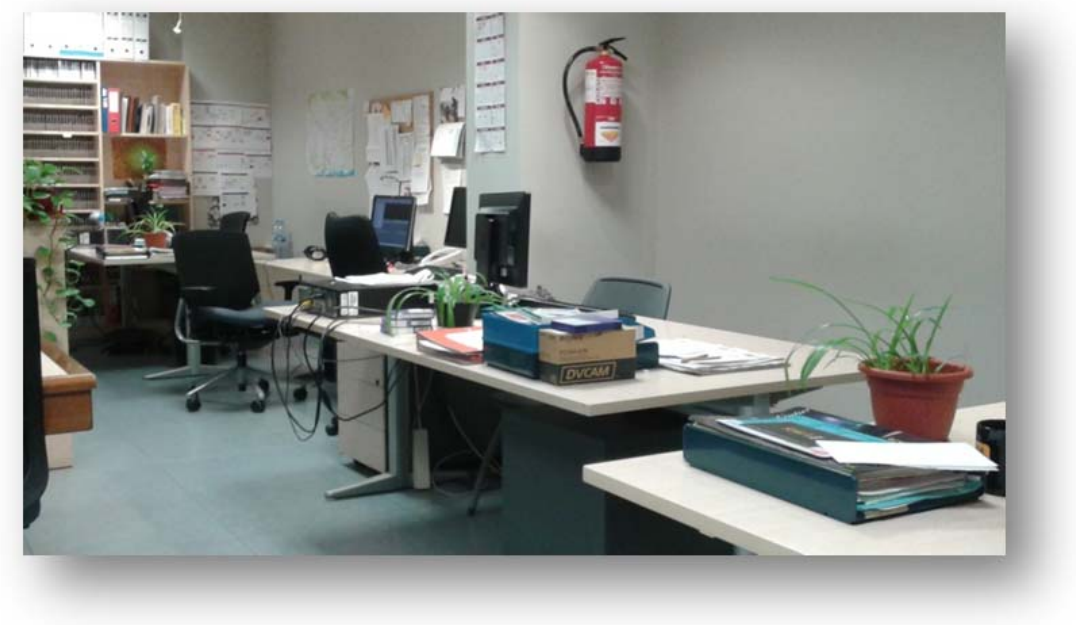

Departament de documentació de Barcelona Televisió

Radio Televisión Española en Catalunya es un centro de producción situado en Sant Cugat del Vallès que forma parte de la corporación Radio Televisión Española (RTVE). La directora actual del departamento es Dolors Gonzalo y cuenta con un equipo de 26 personas: 16 documentalistas, 4 administrativos de videoteca, 2 documentalistas de digitalización, 1 documentalista de radio y 2 gestores de contenido. Los ámbitos de trabajo donde interviene el departamento son: informativos, deportes, programas de entretenimiento, web, documentación escrita y digitalización de documentos antiguos.

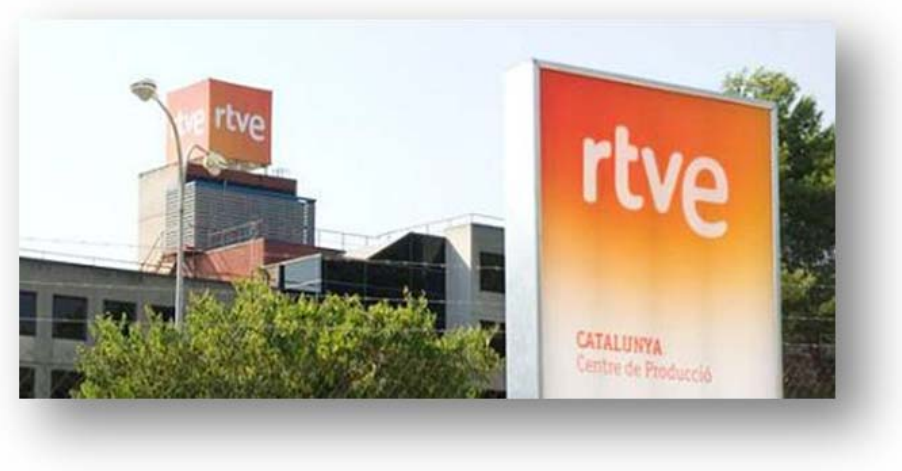

Estudis de Radio Televisió Espanyola (Sant Cugat del Vallès) 
Televisió de Catalunya es la televisión pública catalana que forma parte de la Corporación Catalana de Medios Audiovisuales (CCMA) y nació en 1983. Aquel mismo año un grupo de documentalistas viajó a Paris, donde aprendieron a analizar los documentos audiovisuales y a constituir un archivo. Actualmente, bajo la dirección de Alícia Conesa, el departamento está formado por 40 profesionales. Los ámbitos de trabajo donde interviene el departamento son: informativos, deportes, programas de entretenimiento, web, documentación escrita y digitalización de documentos antiguos.

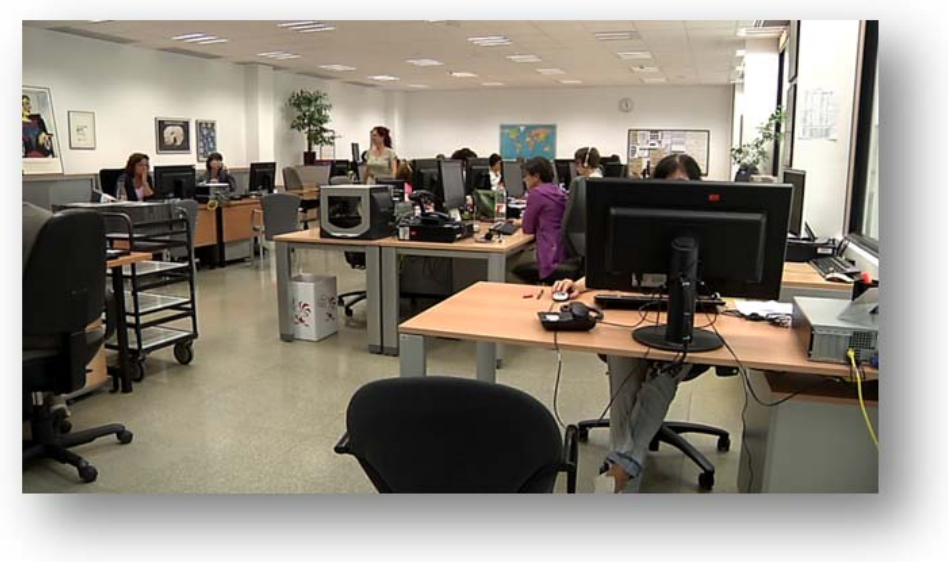

Departament de documentació de Televisió de Catalunya

8tv es una televisión privada de Catalunya perteneciente al Grupo Godó, cuyo eslogan es "la privada de Catalunya". El departamento de documentación de 8tv nace en 2011 con la entrada del periodista Josep Cuní en la cadena y de su programa estrella 8 al dia. El departamento se dedica exclusivamente a gestionar el material generado por el programa y está formado por dos documentalistas; Caterina Riera y Soraya Lozano.

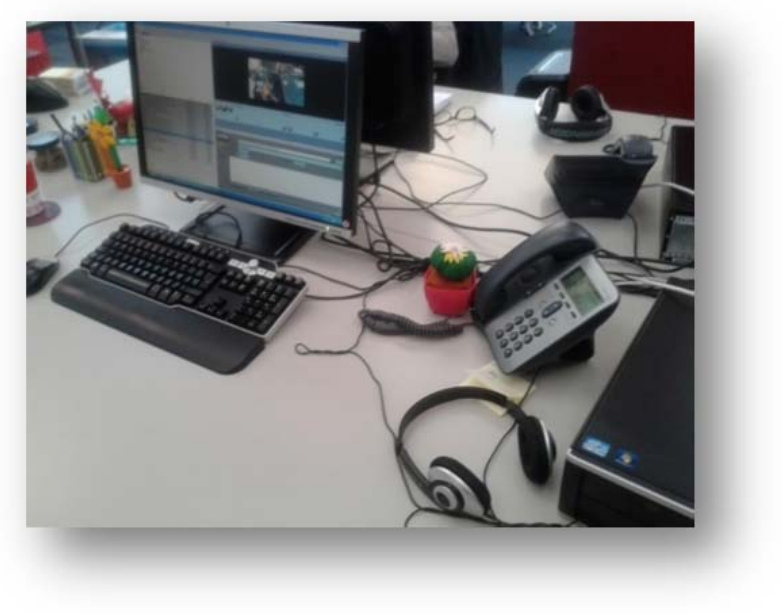

Departament de documentació de 8tv 


\section{Software}

"El sistema de archivo es Tarsis y se integra muy bien con otras aplicaciones como por ejemplo iNews (AVID), que es el sistema de redacción de noticias. Este sistema permite incorporar metadatos del programa iNews para hacer una pre-catalogación. Todo el mundo tiene acceso a buscar, descargar el material y usarlo" BTV

"El material de producción lo gestionamos con AVID, un sistema externo. A través de los programas Asist y Access hacemos la catalogación para tenerlo almacenado dos años (en producción). Pasados los dos años, enviamos el material a nuestro gestor documental que se llama a ARCA (archivo)" RTVE

"Utilizamos Digition, un programa de gestión audiovisual que permite almacenar las imágenes y añadir metadatos. Algunos datos vienen dados de producción, entran al archivo junto con al alta, la baja y los keyframes. El trabajo del documentalista es añadir metadatos. Digition lo utiliza toda la casa, es adaptable y funciona a través de grupos" TVC

Se constata el uso de paquetes de software especializado en los centros analizados: AVID y Tarsis en BTV; AVID y $A R C A$ en RTVE, Digition en TVC, y VSN en 8tv. La distinción entre su uso para la gestión de la producción y la gestión del archivo se puede ver en la tabla 1.

En lo que se refiere a la producción audiovisual, estos sistemas permiten, dentro del mismo software, reservar un espacio de trabajo para cada departamento de la televisión. De este modo, es común ver como periodistas y documentalistas comparten software, hecho que les permite estar más conectados en el traspaso de la información que se encuentra en estado de producción.

Por su parte, el material que ya no está en producción sino en archivo, se gestiona a través de programas más enfocados a la documentación. Estos programas de archivo pueden pertenecer al mismo paquete de software que el de producción (caso de TVC y 8TV) o bien ser independientes de los anteriores (caso de BTV y RTVE).

A diferencia de Digition, un sistema de gestión propio de TVC, en los otros casos nos encontramos con software adquiridos. 


\begin{tabular}{|c|l|l|}
\hline TV & $\begin{array}{c}\text { Programa de gestión de } \\
\text { material en estado de } \\
\text { producción }\end{array}$ & $\begin{array}{c}\text { Programa de gestión de } \\
\text { material de archivo }\end{array}$ \\
\hline BTV & $\begin{array}{l}\text { AVID (incluye iNews; sistema } \\
\text { de redacción de noticias) }\end{array}$ & \begin{tabular}{l} 
Tarsis \\
\hline RTVE
\end{tabular} \\
\hline TVC & AVID & ARCA \\
\hline 8tv & Digition & Digition \\
\hline VSN & VSN Archive \\
\hline
\end{tabular}

Tabla 1. Software especializado en las televisiones

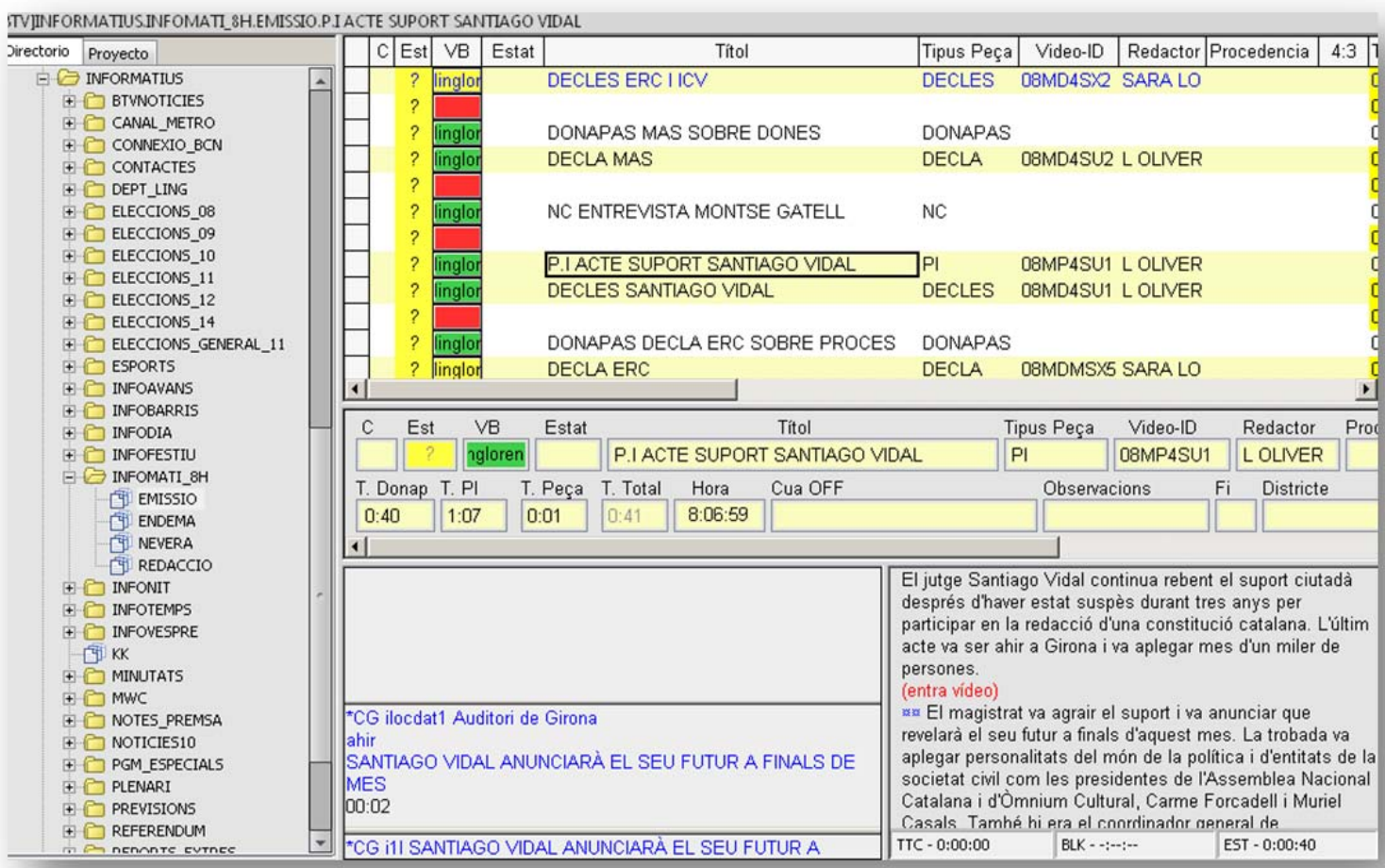

iNews. Barcelona Televisió 


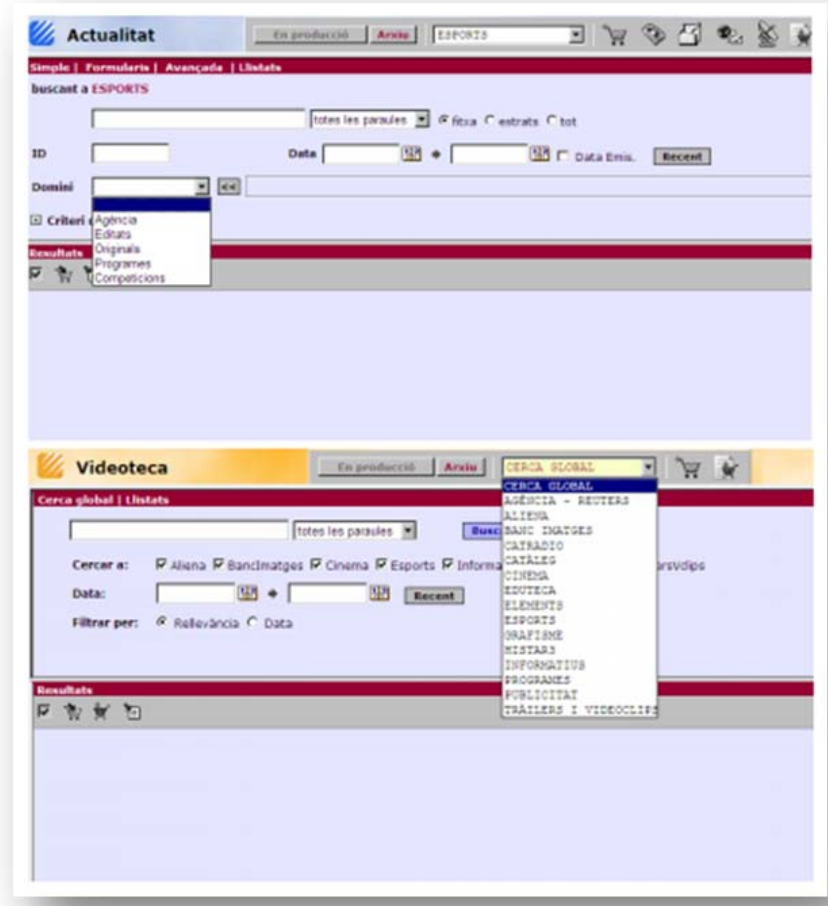

Digition. Televisió de Catalunya

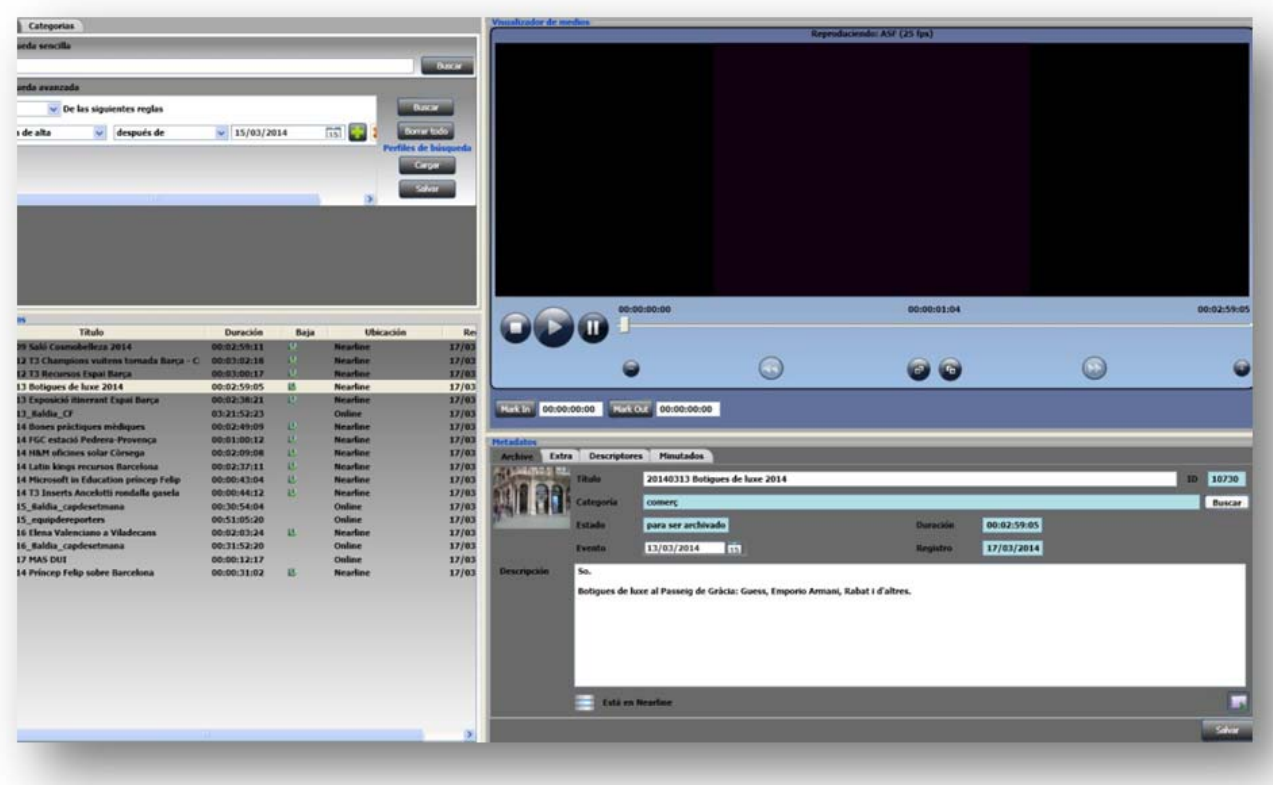

VSN Archive. 8tv

Cuadernos de Documentación Multimedia Vol. 26. 


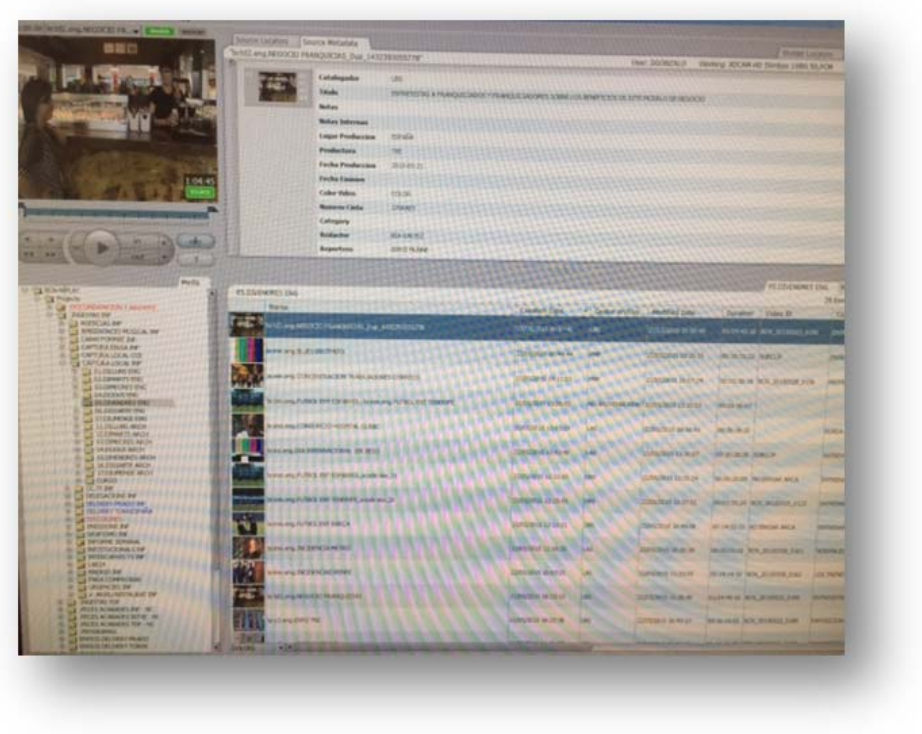

AVID. Radio Televisió Espanyola

\section{Selección}

"El criterio es guardar todo lo que se ha emitido y hacer una selección de los originales. El primer criterio es lo de los editores, nosotros podemos decidir si realmente aquello interesa o no" - BTV

"Las emisiones nos las quedamos siempre y los originales, prácticamente siempre, haciendo un poco de selección en función de la relevancia y de lo que ya tienes" - RTVE

"Guardamos todos los Paralelos de Antena y los Preparados Para Difusión (PPD), que son toda la emisión. La selección de originales la hacemos los documentalistas, a veces ya nos viene seleccionada por los propios periodistas, les pedimos ayuda. Los criterios son de valor documental y patrimonial" TVC

La selección de los materiales que han de formar parte del archivo de la cadena es una de las funciones tradicionalmente importantes de un centro de documentación televisivo.

Dicha selección la efectúan los documentalistas en tres de las cuatro televisiones estudiadas (BTV, TVC y RTVE), si bien en todos los casos se tienen en cuenta los criterios previos de los profesionales de la redacción, especialmente en BTV. En 8tv en cambio la selección documental la realizan otros profesionales de la redacción, y los documentalistas no intervienen en la misma.

En cuanto al tipo de materiales que se selecciona, hay que distinguir entre los materiales de emisión y los originales de rodaje o brutos. Sobre los primeros, hay que tener en cuenta que la política de preservación obliga a guardar en el archivo audiovisual todo lo que se emite. Por tanto, donde realmente hacen selección 
los documentalistas es en los materiales originales de rodaje, excepto en 8tv, donde como hemos visto éstos ya no llegan.

No suele existir una política clara con este segundo tipo de materiales, como sucede con las emisiones, sino que depende del criterio del centro de documentación o del documentalista, que selecciona las imágenes en función de su relevancia, teniendo en cuenta fundamentalmente dos elementos: el valor patrimonial y el valor de reutilización del material.

\section{Análisis documental}

"Catalogamos bajo nuestros criterios propios. La descripción con material propio es más detallada. Se obtienen datos previos de iNews, trabajo que te ahorras después para catalogar. Tenemos un control de descriptores que es una lista plana, pero no tiene la estructura de un thesaurus - BTV

"Hubo una comisión del proyecto ARCA que estuvo trabajando en base a las normas que ya teníamos. Si es material nuestro se acostumbra a catalogar con más detenimiento, y si no tenemos los derechos, más simple. Cuando catalogamos con AVID no lo hacemos con thesaurus, sino que ponemos algunas palabras que nos coincidan. Después, con ARCA, se conecta con el thesaurus" - RTVE

"En los inicios se tomaron unos acuerdos en común, durante la creación del primer thesaurus. Se aprendió en París, en el Instituto Nacional de Audiovisuales de Francia. Tenemos un thesaurus creado por nosotros mismos y lo tenemos introducido dentro del Digition" - TVC

El análisis documental (o "catalogación", como se denomina usualmente en los centros esta labor) del material audiovisual de archivo ha sido y continúa siendo una de las funciones fundamentales de la documentación en televisión. Aunque en la descripción documental se utiliza y se aprovecha la obtención previa de datos, es decir, el documentalista recibe las imágenes con unos metadatos introducidos por los periodistas (o por las agencias, en su caso), éstos posteriormente se completan (y se modifican si es necesario) con un nivel de descripción más elevado.

No existen unos estándares de análisis documental en los departamentos de documentación televisivos, sino que cada centro confecciona su propio vocabulario documental construido a partir del lenguaje periodístico y de recomendaciones de normativas diversas. De las televisiones estudiadas, los dos grandes (RTVE y TVC) mantienen thesaurus de elaboración propia, mientras que las pequeñas (BTV y 8TV), emplean lenguajes documentales propios que no llegan a esta categoría.

Por otro lado, los materiales de creación propia de cada televisión tienen un análisis documental más rico y detallado, mientras que los materiales ajenos (adquiridos a otras fuentes como agencias, productoras, etc.) se analizan de manera más elemental o simple. Asimismo, se analizan con más detalle los programas informativos que los de entretenimiento. En documentación de 8TV, como ya hemos ido viendo, esta segunda opción ya no existe.

\section{Digitalización y nuevos flujos de trabajo}

"Con la digitalización tenemos más visibilidad. Ahora tienes el documento en baja resolución, consultable. Tenemos documentos antiguos desde el 1994, pero el trabajo regular del departamento 
no permite hacer digitalización. Retrospectivamente no se hace, sólo si es algo muy anecdótico, que sabes que lo usarán" - BTV

"El 2010 es un momento clave en cuanto a producción, cuándo ya estamos completamente digitalizados. La videoteca antigua no está digitalizada del todo, estamos en proceso" - RTVE

"La digitalización ha influido en agilidad y facilidad de acceso al documento final. Nos va muy bien para elaborar documentales. Las cintas se digitalizan con los magnetoscopios; se hace cada día" - TVC

La transición del formato analógico al formato digital ha ido cambiando las bases de datos referenciales por sistemas de gestión audiovisuales que permiten consultar el documento en baja calidad. La excepción a la existencia a una videoteca analógica previa a la digital es 8tv, que ya nació en formato digital.

El trabajo en formato digital ha dotado de agilidad a los departamentos, ha modificado las formas de trabajar anteriores y ha generado nuevos perfiles profesionales como el gestor de contenidos, el técnico en digitalización, el buscador especializado o el documentalista-periodista.

Por otro lado, los proyectos de digitalización de los documentos antiguos son competencia de los departamentos de documentación. En TVC y TVE se continúan transformando diariamente decenas de cintas de material de archivo por parte de personal especializado. En BTV la digitalización no es una tarea regular, sino que se hace de manera extraordinaria.

\section{Usuarios}

"Suelen venir a pedir ayuda. Si lo buscan todo ellos, tú pierdes un poco el contacto de lo que estás haciendo. Hacemos formación de usuarios cuando hay un cambio de software" - BTV

"Tenemos documentalistas trabajando en redacciones. Los periodistas hacen menos búsquedas de las que deberían. Tenemos personas que se encargan de las búsquedas. Hacemos formación de usuarios, de ARCA y de AVID (...) En relación a otros usuarios, conozco un poco TVC porqué nos piden imágenes para programas tipo "Sense Ficció" o "30 minuts", son clientes" - RTVE

"Tenemos documentalistas que trabajan con los periodistas. Los usuarios buscan, esto es querido, pero igualmente hacemos un montón de búsquedas. Los administradores del Digition (documentalistas) hacen cursos para poder consultarlo bien (...) Por otra parte, he hecho consultas a usuarios ajenos, por ejemplo Televisión Española" - TVC

La entrada del documentalista en la cadena de producción lo hace estar en constante contacto con la redacción de la televisión. Esta es una forma de trabajo que se aprecia que está creciendo, especialmente en las televisiones grandes. El redactor necesita la nueva imagen ingestada (introducida en el sistema) e indexada para la fase de producción y a la vez puede necesitar la imagen de archivo para ilustrar la nueva. Esto se convierte en una demanda constante de información, hecho que ha encaminado a muchos documentalistas a trabajar en las mismas redacciones de los programas, como sucede en TVC y RTVE.

En cuanto a la búsqueda de imágenes, la idea básica y común en todas las televisiones es que los periodistas sean capaces de encontrarlas por ellos mismos. No obstante, a pesar de la formación de usuarios, los 
periodistas demuestran carencias para usar los sistemas de búsqueda y siguen acudiendo puntualmente a los documentalistas, quienes también realizan las búsquedas más elaboradas. También en otras ocasiones los documentalistas se adelantan a las peticiones de búsquedas, como se abunda en el apartado siguiente.

Asimismo, la búsqueda de imágenes también puede producirse para departamentos de documentación de otras televisiones, como se ha constatado entre TVC y RTVE.

\section{Productos documentales}

"Cuando hay algún acontecimiento importante hacemos dosieres temáticos. Se cuelgan todos los documentos que pueden ser válidos para las personas que tengan que trabajar con esta información" RTVE

"Hacemos diversas cosas; por ejemplo el "archivo catálogo": es una ficha de cada uno de los programas que tenemos" - TVC

La elaboración de productos documentales, a iniciativa propia o no, por parte de los departamentos de documentación, es una función que se reivindica en los últimos años como una de las que debe potenciar el actual perfil de documentalista audiovisual.

En las televisiones grandes, TVC y RTVE, se generan diversos productos documentales, como por ejemplo las previsiones, los dosieres temáticos o los catálogos. Son paquetes de información con un denominador común: una persona pública, una institución, un programa de televisión, un acontecimiento político importante, una efeméride deportiva, etc. Se recogen imágenes y/o información en general al respeto para que los periodistas estén al día de la cuestión y dispongan de material necesario en caso de que lo necesiten. El destino de estos productos documentales es la redacción del medio y no directamente el usuario final.

Por su parte, en las televisiones pequeñas la situación es distinta. En BTV no se realizan de manera sistematizada pero sí en ocasiones, y en 8tv no se elaboran productos documentales.

\section{Cadena de producción y propuestas de contenido}

"Estamos en la cadena de producción, y al generar contenidos también. A veces sugerimos" - BTV

"Ahora estamos al principio, en medio y al final de la cadena de producción. Podemos sugerir temas, sobre todo con material antiguo" - Dolors Gonzalo, RTVE

"Podemos opinar y dar información. En informativos quizás los periodistas son más suyos" - TVC

La digitalización ha permitido al documentalista de las televisiones entrar en la fase de producción de programas. Los documentalistas son los primeros en recibir los documentos, los tratan documentalmente en la fase de producción y, al final, los catalogan para ser archivados. El conocimiento del archivo de la cadena permite a los documentalistas hacer sugerencias y propuestas a los periodistas en todos los casos estudiados, menos en 8tv. 


\subsection{Futuro profesional}

"Supongo que la digitalización seguirá adelante y el perfil profesional será cada vez más tecnológico" BTV

"En los próximos 5-10 años, me imagino un departamento muy tecnológico" - RTVE

"Creo que habrá menos documentalistas y quizás no podremos hacer descripciones tan detalladas. Cada vez habrán más nuevas tecnologías" - TVC

Cuando se pregunta a los documentalistas por su visión del futuro de los departamentos de documentación y de su actividad profesional, destacan la tecnología como el factor fundamental de la evolución y de los posibles cambios. La visión del perfil profesional futuro con un importante peso tecnológico es una constante.

Otro aspecto señalado para los próximos años es la continuación de los procesos de digitalización iniciados, que ha introducido un entorno de trabajo que exige a las televisiones la sustitución de sistemas analógicos por sistemas digitales en los procesos de producción, emisión, almacenamiento y archivo. La transición iniciada está todavía en proceso y no ha finalizado.

Por último, también se mencionan algunas amenazas, como las posibles reducciones de personal, o en el caso de la televisión pequeña, 8tv, la dependencia total del departamento de la continuidad de un programa de televisión concreto.

\section{CONCLUSIONES}

\section{Televisiones grandes y televisiones pequeñas}

La dimensión de los departamentos de documentación es, lógicamente, proporcional a la de las televisiones a las cuales pertenecen. Cuántas más grandes son las redacciones y el volumen de producción y de usuarios, más soporte documental necesitarán. Los departamentos de las dos televisiones grandes estudiadas, TVC y RTVE en Catalunya, disponen de cuarenta y veintiséis documentalistas respectivamente y se pueden permitir trabajar en espacios diferentes, como por ejemplo en TVC, donde Informativos y Programas están en edificios diferentes $\mathrm{O}$, incluso, enviar documentalistas a las redacciones de los programas como también pasa en RTVE.

En otros contextos, como por ejemplo BTV, una cadena de cobertura local, o 8tv, una televisión privada emergente con poca programación, vemos que el número de documentalistas en sus departamentos dista entre dos y seis, el trabajo documental tiene menos funciones que en las anteriores, y en líneas generales está más enfocado a la gestión del material audiovisual y no tanto al servicio al usuario.

\section{Software}

En el proceso de producción de programas, el documentalista audiovisual suele trabajar en un workspace integrado en el software que usan los periodistas y cuando las imágenes ya se han emitido y pasan a formar parte del archivo, el documentalista usa otro software, éste ya más enfocado a la documentación (con 
búsqueda avanzada, etiquetado, descriptores, etc). Es lo que sucede por ejemplo en RTVE, en donde se utiliza AVID para Producción y ARCA para Archivo.

Es menos frecuente el uso de software que integre en un mismo sistema el espacio de Producción y el espacio de Archivo. Es el caso de Digition en TVC, en el que el mismo sistema de producción incorpora el archivo, donde es consultable también todo el material histórico.

\section{Selección}

La selección del material que formará parte del archivo se continua realizando en los departamentos de documentación de las televisiones estudiadas, excepto en el caso de la sección de documentación más pequeña, la de 8tv, en que esta función no se realiza.

No existen como tal unas políticas de selección y preservación estandarizadas de los originales de rodaje por parte de los departamentos de documentación. Estas imágenes se guardan o no en función del criterio establecido por cada centro o por el criterio personal del documentalista a partir de dos premisas básicas: valor patrimonial o valor de reutilización. Este hecho implica que el profesional de la información tiene que estar al día de la actualidad social, política y deportiva y tener conocimientos básicos sobre otras disciplinas para poder valorar con rigor si las imágenes en cuestión son o no relevantes.

\section{Análisis documental}

La función de análisis documental continua siendo importante, a pesar de los cambios de los últimos años por las facilidades en la introducción de metadatos -automáticamente o por otros profesionalespreviamente al trabajo del departamento de documentación. Las televisiones, a diferencia de las bibliotecas, archivos y museos, que disponen de modelos normalizados, construyen su propio vocabulario documental a partir del lenguaje periodístico y de recomendaciones de algunas normativas tipo ISBD o $A A C R$.

En las televisiones el concepto de usuario es diferente, puesto que éste y el documentalista forman parte de la misma cadena de trabajo, lo que hace que el documentalista se adapte a él en cuanto al software y también al tipo de descripción documental empleada; de hecho, el usuario también ha colaborado en el análisis documental (en la introducción de metadatos previa a la validación final por parte de documentación).

\section{Digitalización y nuevos flujos de trabajo}

Hasta ahora, con los sistemas analógicos, los documentalistas recibían las imágenes una vez ya emitidas, las catalogaban y las guardaban en el archivo. Actualmente, el documentalista es el primero en recibir las imágenes que se han grabado. Su tarea es tenerlas catalogadas y accesibles desde el inicio para que los usuarios de producción puedan empezar a trabajar con ellas. Esta entrada en la cadena de producción convierte al documentalista en un agente clave en el proceso de creación de programas. Esta realidad genera nuevos perfiles profesionales en los departamentos como por ejemplo el gestor de contenidos, el técnico en digitalización, el buscador especializado o el documentalista-periodista.

Por otro lado, los documentos antiguos suponen un elemento de proximidad entre el documentalista y el periodista. Las redacciones constantemente necesitan imágenes de archivo para ilustrar sus reportajes, 
noticias y/o promociones. Precisamente en BTV y en 8tv, donde no disponen de un fondo antiguo similar al de RTVE o TVC, es donde se constata una relación más distante con el usuario.

\section{Productos documentales}

Los documentalistas son previsores y se anticipan a aquello que probablemente se les pedirá, lo que sucede especialmente cuando se trata de un gran acontecimiento, como unas elecciones, una competición deportiva importante, etc. Cumpliendo esta tradicional función previsora de la documentación, pero no solamente con este objetivo, se elaboran de manera sistematizada productos documentales en las dos televisiones grandes estudiadas (RTVE y TVC), mientras que en BTV se pueden elaborar esporádicamente y en 8tv no se realizan... El objetivo y el destino de tales productos, no obstante, es su uso por parte de la redacción y de los periodistas; no se suelen elaborar directamente por Documentación para el usuario final.

\section{Cadena de producción y propuestas de contenido}

Relacionado con el punto anterior, en las televisiones grandes se constata el papel de sugeridor de contenidos por parte del documentalista. Este es quien mejor conoce el archivo y por lo tanto se puede permitir plantear temáticas o ilustrar reportajes por él mismo. A veces es simplemente recordar una efeméride. Pasa de igual manera con la web, donde también se difunde contenido de archivo. Excepto en $8 \mathrm{tv}$, las otras tres televisiones aseguran dar imagen fija y en movimiento para los portales web.

\section{Usuarios}

Los periodistas de informativos, que diariamente generan y emiten contenidos, son menos dependientes del departamento de documentación puesto que necesitan resultados inmediatos y la petición de información los haría perder tiempo. Con los programas de entretenimiento, donde la producción de un reportaje se puede planificar con más tiempo, se ayudan mucho más del servicio de documentación para la obtención de imágenes.

La formación en uso del software se hace de manera muy puntual, sólo para actualizaciones del software, y los usuarios olvidan el funcionamiento de los programas. Necesitan apoyo de los documentalistas diariamente. Únicamente en TVC se hacen sesiones formativas. En BTV y RTVE se hacen de manera individual a petición del usuario y en 8tv no se hace.

Por otra parte, los departamentos de documentación cada vez están más relacionados con el ámbito jurídico. Esto está directamente relacionado con la programación ajena y con la compraventa de imágenes entre televisiones, como pasa a menudo, de las cadenas estudiadas, entre TVC y RTVE. Los departamentos de documentación ajenos se están convirtiendo en un nueve colectivo de usuarios y las cuestiones jurídicas en un campo de trabajo emergente. En este sentido, se intuye que la propiedad intelectual se relacionará cada vez más con la profesión del documentalista audiovisual, teniendo en cuenta que ellos son los principales agentes en la adquisición y preservación de los documentos audiovisuales digitales. Los documentalistas se ven obligados a conocer bien la legislación cuando tienen que comprar, vender, ceder, transferir y catalogar documentos. Asimismo, una posible opción sería colocar especialistas en legislación en los departamentos de documentación. 


\section{Futuro profesional}

Todos los documentalistas entrevistados consideran muy importando el avance de la tecnología en los departamentos de documentación, que hace que se esté viviendo un cambio en las funciones tradicionales de los documentalistas. Esta situación puede representar la aparición de nuevos perfiles profesionales y una participación más activa de éstos en la elección, el diseño y la gestión del software documental especializado. Las vinculaciones de los profesionales de la documentación audiovisual con el diseño, la informática, las redes sociales y la propiedad intelectual serán también elementos a tener en cuenta en el futuro de la profesión.

\section{Notas}

1. Las transcripciones literales de respuestas que se muestran corresponden a tres de los cuatro centros estudiados (BTV, RTVE y TVC), ya que se ha acordado no reproducir las declaraciones textuales de las documentalistas de 8 tv a petición suya. 


\section{REFERENCIAS BIBLIOGRÁFICAS}

Agirreazaldegi-Berriozabal, Teresa (2007). Claves y retos de la documentación digital en televisión. // El profesional de la información. 16:5 (septiembre-octubre 2007), 433-442. http://elprofesionaldelainformacion.com/contenidos/2007/ septiembre/05.pdf (2015-1003).

Caldera-Serrano, Jorge (2015). Production Research: el nuevo rol profesional para nuevos tiempos en la gestión de la información audiovisual. // Investigación bibliotecológica. 29: 66. 79-89. http://www.scielo.org.mx/scielo.php?pid=S0187358X2015000200079\&script=sci_arttext (2015-10-03).

Caldera-Serrano, Jorge; Arranz-Escacha, Pilar (2012). Documentación audiovisual en televisión. Colección El profesional de la información; 13. Barcelona: Editorial UOC, 2012.

Caridad Sebastián, Mercedes [et al.] (2011). Documentación audiovisual: nuevas tendencias en el entorno digital. Colección Comunicación audiovisual; 11. Madrid: Síntesis, 2011.

Castillo Blasco, Lourdes; Soler Monreal, Concha (2014). Análisis de los artículos publicados sobre documentación televisiva en España (1984-2014). // BiD: textos universitaris de biblioteconomia i documentació. 33 (diciembre 2014). http://bid.ub.edu/es/33/castillo2.htm (2015-10-03).

Conesa, Alícia (2013). De la videoteca a l'arxiu digital: evolució del Departament de Documentació de Televisió de Catalunya. // $\quad$ Trípodos. 31 http://www.raco.cat/index.php/Tripodos/article/viewFile/262075/349257. (2015-10-03).

De Mon Martín, Adrián; Guallar, Javier (2014). Análisis de las videotecas de las principales televisiones en España. // Cuadernos de documentación multimedia. 25. http://revistas.ucm.es/index.php/CDMU/article/view/47472 (2015-10-03).

Giménez-Rayo, Mabel (2012). La documentación audiovisual en televisión en el mundo 2.0:

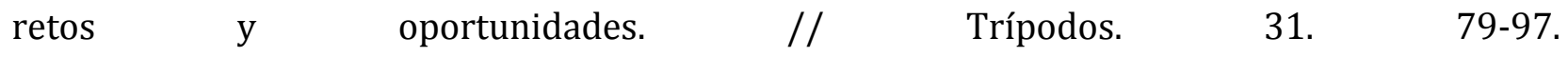
http://www.tripodos.com/index.php/Facultat_Comunicacio_Blanquerna/article/view/39/24 (2015-10-03).

Giménez-Rayo, Mabel; Guallar, Javier (2014). Centros de documentación en televisión y productos documentales. // El profesional de la información. 23:1 (enero-febrero 2014) 13-25. http://recyt.fecyt.es/index.php/EPI/article/view/epi.2014.ene.02 (2015-10-03).

Hidalgo Goyanes, Paloma (2005). La documentación audiovisual de las televisiones. La problemática actual y el reto de la digitalización. // Documentación de las ciencias de la información. 28. 159-171. http://revistas.ucm.es/index.php/DCIN/article/viewFile/ (201510-03). 
Hidalgo Goyanes, Paloma (2013). Patrimonio audiovisual en televisión. // Marcos Recio, Juan Carlos (coords.).Gestión del patrimonio audiovisual en medios de comunicación. Colección Ciencias de la información.Comunicación audiovisual; 18. Madrid: Síntesis, 2013. 53-82.

López-de-Quintana-Sáenz, Eugenio (2007). Transición y tendencias de la documentación en televisión: digitalización y nuevo mercado audiovisual. // El profesional de la información. 16:5 (septiembre-octubre) 397-408. http://dx.doi.org/10.3145/epi.2007.sep.01 (2015-10-03).

López-de-Quintana-Sáenz, Eugenio (2014). Rasgos y trayectorias de la documentación audiovisual: logros, retos y quimeras. // El profesional de la información. 23:1 (enero-febrero 2014) 5-12. http://recyt.fecyt.es/index.php/EPI/article/view/epi.2014.ene.01 (2015-10-03).

López de Solís, Iris; Nuño Moral, María Victoria; Cuadra de Colmenares, Elena de la (2014). Panorama de las fuentes audiovisuales internacionales en televisión: contenido, gestión y derechos. // BiD: textos universitaris de biblioteconomia i documentació. 33 (diciembre 2014). http://bid.ub.edu/es/33/lopez2.htm (2015-10-03).

Mas, Tomeu; Martínez, Virginia (2010). El documentalista audiovisual del Centro de Documentació de Barcelona Televisió. // BiD: textos universitaris de biblioteconomia i documentació. 24. http://bid.ub.edu/24/martinez2.htm. (2015-10-03).

Muñoz-de-la-Peña-Costero, Paz; Meana-Alonso, Sonsoles; Sáez-Carreras, Susana (2014). Cinco años de experiencia digital en los Servicios Informativos de TVE: una nueva gestión de contenidos. // El profesional de la información. 23:1 (enero-febrero 2014) 72-79. http://recyt.fecyt.es/index.php/EPI/article/view/epi.2014.ene.09 (2015-10-03).

Rubio, Albert; Guallar, Javier (2014). Funcions del documentalista en un mitjà de comunicació audiovisual digital. Estudi de cas: RelTV. // BiD: textos universitaris de biblioteconomia i documentació. 33 (diciembre 2014). http://bid.ub.edu/33/rubio1.htm (2015-10-03). 